\title{
Examining the Possible Effects of (mis)matches between EFL Teachers' and Students' Perceptions of L2 Writing Assessment on Students' Writing Achievement Scores
}

\author{
Mostafa Tajgozari $^{1^{*}}$, Zahra Alimorad ${ }^{2}$ \\ ${ }^{1,2}$ Shiraz University, Shiraz, Iran \\ *Corresponding author: s.mtajgozari@ rose.shirazu.ac.ir
}

\begin{abstract}
The present mixed-methods study intended to explore Iranian EFL teachers' and students' perceptions of assessment of students' written performance and the effect of any possible (mis)matches on students' achievement. To these aims, a convenient sample of teachers $(\mathrm{N}=5)$ and students $(\mathrm{N}=30)$ from different classes and institutes in Iran was recruited to participate in the study. In the first phase of the study, all of the participants, both teachers and students, were interviewed to determine their perceptions of writing assessment. In the next phase, students were asked to write about a topic and in the last phase, the writings were assessed and scored by both teachers and students. During this phase, teachers and students were asked to think aloud while assessing the writings. Results indicated that a) based on teachers' perceptions, language, punctuation, content, organization, and communicative achievement are important factors in assessing a piece of writing, respectively. Also, teachers believed composition writing is the best activity to assess students' writing and the teachers should stick to their own perceptions while assessing writing and not use available rubrics. Moreover, all of them believed that scoring writing is always inaccurate and subjective; b) based on students' perceptions, grammar and spelling are important factors in the assessment of a piece of writing, respectively. They also mentioned that the ability to write can be assessed through composition writing and their teachers should utilize their own perceptions rather than utilizing a standard rubric. In addition, most of them considered scoring writing to be always inaccurate and subjective; c) students' perceptions of writing assessment affected their writing scores. That is, based on their own perceptions of criteria for writing assessment, the students expected to receive higher scores than the ones given by their teachers.
\end{abstract}

Keywords: Assessing writing, criteria, perceptions, students, teachers. 


\section{Introduction}

Brown (2006) views perceptions as subjective beliefs and evaluations of someone's work which play an important role in the realm of language teaching and learning since they underlie teachers' and students' beliefs, opinions, and actions. He further argues that differences in students' and teachers' perceptions may result in students' loss of interest and motivation in class. Also, potential mismatches between the perceptions of students and those of their teachers can have negative effects on learners' sense of satisfaction with their English class as well as on their final achievement (Williams \& Burden, 1997), which highlights the importance of investigating teachers' and students' perceptions in education in general and language teaching and learning in particular.

Second language (L2) writing has been studied across different languages (Kaplan \& Grabe, 2002) and has become a means for access to knowledge, power and resources (Crowley, 1998; Leki, 2003). Reilly (2005), believes that in the last two decades, since writing is accepted to be an important activity and the most demanding language skill, there has been a surge in the introduction of new approaches to help students become better writers. Nevertheless, teachers see writing as a skill which is challenging and, consequently, not a desirable activity for language learners (Reilly, 2005).

Considering the importance of L2 writing, it can reasonably be argued that writing assessment, too, assumes paramount importance in L2 learning contexts. The importance of assessment has widely been acknowledged, especially by those who deal with teaching and learning. Brinke et al. (2007), for instance, believe that assessments are at the center of the educational process because they directly impact on the students' learning processes. Moreover, it has been emphasized by Dahlgren (1984) that assessing learners' performance is an important task which cannot be ignored and has a strong effect on learners' approaches to learning and outcomes of their studies. Also, Struyven, Dochy, and Janssens (2005), argued that the importance of assessment and the significant effect it can have on students' performance cannot be ignored.

Given the importance of writing assessment and considering the need for attempting to match teachers' and students' perceptions of writing assessment, it seems necessary to conduct an in-depth analysis and examination of these two groups' perceptions of this issue. Therefore, the present study intended to investigate Iranian EFL institute teachers' and learners' perceptions of writing assessment as well as the impact of any possible (mis)matches between teachers' and students' perceptions on learners' achievement. 


\section{Literature review}

A plethora of studies attempted to examine teachers' and students' perceptions of writing assessment. As an example, Montgomery and Baker (2007) attempted to investigate (1) how much local and global written feedback teachers gave, and (2) how their self-assessments and students' perceptions of this feedback coordinated. Teachers and students in an ESL intensive program were studied and their perceptions of teacher written feedback on compositions were explored and the results were compared to their actual written feedback. Findings showed that teachers' self-assessments and student perceptions of teacher-written feedback coordinated well; however, students expected receiving more feedback than teachers perceived necessary giving.

In another study, Neumann (2014), investigated what students perceived to be the impact of their teachers' assessment criteria on their way of writing and learning in the L2 writing classroom. The students in this study apparently attempted to understand their teachers' expectations and then, tailored their writing to meet those expectations. Students may have avoided particular structures in order to satisfy the teachers' expectation for accuracy rather than focusing on their learning and taking risks to experiment with new language and expand their linguistic repertoire. Also, results indicated that the students were aware of their teachers' primary focus on accuracy as an assessment criterion and could enumerate particular areas of weakness that their teachers had previously identified in their writing using the evaluation grid.

In a mixed-methods study, Wolsey, Lapp, and Fisher (2012), compared teachers' and students' perceptions of academic writing. To gather the necessary data, they made use of surveys, interviewed students and teachers, and examined students' written work. The participants of the study were all 10th-grade students and their teachers at one charter school. Results of their study suggested that students' perceptions which were built on their earlier experiences with academic writing tasks clearly differed from those of their teachers. Hence, while the students defined or conceptualized academic writing largely in terms of the local operations, their teachers tended to define their notions of academic writing in a more robust way.

Eun (2015), studied the views of students and teachers regarding feedback in English writing course and attempted to find out what sort of problems the two groups had when they exchanged feedback. To this end, three Korean teachers and 99 of their university students from different ages, majors, and English proficiency levels participated in surveys. All of the students were enrolled in the Practical 
English writing course as a general class. Findings indicated that (1) numerous students rated themselves fair or poor writers, meaning that they were not confident in their writing ability; (2) extensive vocabulary was selected as the most important factor affecting writing by students, while for teachers, grammar was very important; (3) from the students' point of view, the concept of feedback was defined in several ways including grammatical error correction, and amendment of overall organization of writing. However, teachers defined the same concept as drawing out students' writing motivation, and helping them overcome their fear and build up confidence; (4) both groups agreed about the feedback they exchanged; nevertheless, some of them also showed disagreement, which may have resulted from their different viewpoints about the concept of feedback.

As the literature review showed, although numerous studies have so far been done which explored or compared teachers' and students' perceptions from diverse perspectives, to the best of the present researchers' knowledge, no study, especially in the context of Iran, has focused on (mis)matches between EFL institute teachers' and students' perceptions of writing assessment. Additionally, the effect of potential (mis)matches between these two groups' perceptions on students' learning outcomes warrants further investigation and examination. All in all, this study was an attempt to bridge these gaps in the literature.

Based on the above-mentioned objectives, the study attempted to seek answers to the following research questions:

1. How do Iranian EFL teachers' and students' perceptions of L2 writing assessment compare?

2. How do teachers' assessments of students' L2 writings compare with their students' perceptions of their own performance in terms of the scores assigned to their writings?

\section{Method}

\section{Participants}

The participants of the present study were EFL instructors and learners in three institutes in Iran. The study was conducted in 5 different classes with 5 teachers and 30 learners at the intermediate level who were selected using convenient sampling. As for the students, their age ranged from 14 to 23 years old with an average age of 17 . They were 18 female and 12 male students. Most of the students $(\mathrm{N}=23)$ had been learning writing for more than two years. Students' English 
classes were the main source of training which prepared them for writing courses. As the proficiency level of the learners had already been estimated by the institutes, there was no need to administer a placement test. In fact, before entering any level in the institutes, all learners take a placement test and the criteria for promotion to another level are fixed in those institutes. Regarding teachers, their age ranged from 29 to 37 years old with the average of 32 years. They were three female and two male teachers. They had not received any formal training in assessment in general and assessment of writing in particular.

\section{Instruments}

Given that the main part of this study was qualitative, the instruments for collecting data were interviews and concurrent think-aloud protocols for both groups of participants. There were 13 interview questions, which were drawn from available literature on writing assessment. The interviews were conducted in their native language (i.e., Persian) for the students because the target language could have acted as a barrier to clear and concise expression of ideas. Their answers were translated into English by one of the researchers. The researchers, then, gave some of those translations to the students and asked them whether they had accurately described their perceptions. This is called member check in qualitative research and contributes to the trustworthiness of the study (Ary, Jacobs, \& Sorensen, \& Razavieh, 2010). But, all of the teachers preferred to be interviewed in English. All interviews and think-aloud parts were audio recorded and later transcribed for further analysis. The rationale behind the interviews and concurrent think-aloud protocols was to uncover both groups of participants' perceptions and to infer their actual practice, respectively. They were interviewed one by one and each interview lasted about 15 minutes. In think-aloud protocols, both teachers and students were asked to simultaneously grade the writings and explain what they were doing as well as the criteria they were considering while they were assessing the writings.

\section{Materials}

Learners were asked to write about a specific topic determined by the researchers and an experienced writing teacher and assigned by their teachers. The topic of the writing, "Describe a place you enjoyed visiting", was the same for all students in all the 5 classes. An attempt was made to choose a topic familiar to the learners in a way whose difficulty level was appropriate for them and it did not bias a specific group of learners so that they could use their background knowledge as well as their knowledge of vocabulary and grammar to write about it. 


\section{Data Collection and Analysis Procedures}

This study constituted three main phases. In the first phase and at the outset of the study, teachers and learners were interviewed to determine their perceptions of writing assessment. In the second phase, learners were asked to write about a specific topic. Finally, in the last phase, teachers and students were asked to assess and rate the writings. Each teacher assessed all his/her students' writings and assigned a score to each one. Each student, however, assessed only his/her own writing.

As for data analysis, both students' and teachers' perceptions were analyzed to find similar themes and also compare different factors which they mentioned. Moreover, the scores which students and teachers gave to the writings were analyzed using descriptive statistics and running an independent samples t-test to compare the writing scores of teachers and students in an attempt to uncover the effect of any potential (mis)matches between these two groups' perceptions of L2 writing assessment on students' achievement scores.

\section{Results and discussions}

\section{A comparison of teachers' and students' perceptions of $\mathrm{L} 2$ writing assessment}

In order to answer the first research question, the researchers compared both groups of participants' perceptions. Results indicated that while teachers mentioned composition writing, open-ended questions, and summarizing as activities which can be used to assess writing, students believed that writing can be assessed through composition writing and writing definitions of terms and concepts. For instance, Teacher 1 said, 'I believe students should be asked to write a composition about a general topic and then correct the writings. By composition writing, the teacher can easily understand students' writing ability.' Teacher 4 also said, 'Well, asking students to write a composition is a useful way of assessing their writing ability. You can find out whether they are grammatically accurate or not.' Teacher 3 added, 'To assess students' writing, I believe that they should be given openended questions that gets them writing. Also, they should be asked to write about a topic every two or three sessions.'

One of the students said, 'Our teacher usually asks us to write about a topic. We have twenty minutes to write and then he assesses and grades the writings.' Another student said, 'Besides composition writing, writing can be assessed through writing definitions, I think. Our teacher gives us some terms and concepts 
which we have to write about and define. Then, she corrects our responses with regard to grammar and lexicon.'

Both groups believed that composition writing is the best activity to assess writing; nevertheless, their perceptions differed with regard to other activities; namely, open-ended questions, summarizing, and writing definitions of the words.

Regarding the participants' perceptions of important criteria for assessing writing, teachers stated language, punctuation, content, organization, and communicative achievement as important factors, respectively while students mentioned just grammar and spelling. All teachers believed that the language (grammar and vocabulary) and punctuation are the most important criteria. For example, Teacher 5 said, 'Whether students use a wide range of vocabulary and structures accurately or not affects their scores.' Also, Teacher 4 pointed out, "The language is very important. I think when assessing students' writing, the accuracy and appropriateness of grammar and lexical recourses should be checked." Teacher 4 stated, 'Punctuations are used to create sense and clarity in sentences. They also act as aids to the understanding of writing; so, I perceive they are important in assenting students' writing.'

Four of them emphasized that content is the next important factor. Teacher 1 said, 'Students' writing should be relevant to the topic and task and teachers should check if students have done what they were asked to do.' Also, Teacher 3 maintained, 'well, content is another factor which I think should be checked while assessing students' writing. It should be checked whether students have addressed different parts of the writing task or whether the writing is relevant to the topic of the writing or not.'

Only two of the teachers stated organization as a criterion in assessing students' writing. Teacher 1 stated, 'the writing should be organized in a way that the main ideas of the writing to be easily recognizable to the teacher. Also, a piece of writing should be logical and ordered.' Just one teacher believed communicative achievement, the focuses on how appropriate the writing is for the task, could be an important factor in this regard. He said, 'Communicative achievement is also an important factor in writing, and I think the teachers should check it while assessing students' writing. Students should use the appropriate tone and register in their writings.'

On the other hand, most of the students $(\mathrm{N}=24)$ believed that grammar is the most important criterion in assessing writing. One of the students said, 'I think grammar is very important in assessing a piece of writing. We have to write as accurately as possible, with regard to grammar, to get a good grade.' As another example, one 
other student stated, 'A piece of writing should be grammatically accurate. I think in assessing writing, we need to focus on grammar to see whether the sentences are correct with this regard or not.'

Fewer than half of them stated spelling as the next important criterion in assessing a piece of writing. As an example, one of the students mentioned, 'Well, spelling is very important in a piece of writing. While assessing writings, we should check the spelling of the words and if necessary, write a comment for the writer to correct it later.'

Also, while three of the teachers believed that a multiple-draft approach should be used in classes, two of them did not believe so. As an example, Teacher 3 said, 'Yes I do believe this approach is useful. I think students' writing should be assessed by the teacher and they should provide students with comments. Then, the students, I believe, should revise the writing and give it back to the teacher. Then, he or she grades the writings.' In contrast to this view, Teacher 2 stated, 'No, in my opinion, the students cannot revise the paper. After the writing is finished, they should be graded.'

On the other hand, most of the students $(\mathrm{N}=21)$ believed that they should revise their writings before they are graded whereas the rest of them $(\mathrm{N}=9)$ believed that their first draft should be graded by the teacher without any revision. As an example, one of the students stated, 'Yes, I think we should revise our writings and then, the teacher should grade them. We write the first draft and then the teacher writes comments, gives us feedback and asks us to revise the paper. I think the procedure should be like what I said.' But, another student pointed, 'Well, I don't think so. We should not use this approach. The teacher should ask us to write and then after assessing the writings, she should grade them. We should not revise our writing.'

All of the teachers believed that they should stick to their own perceptions in assessing writing. Teacher 5 said, 'I think students' writing should not be assessed based on standard or available rubrics. Assessing the writings based on a rubric is time-consuming so I believe that students' written performance should be assessed based on teachers' perceptions.' Teacher 1 said, 'Not specifically. I think a teacher knows what available rubrics emphasize on and should try to take advantage of them in assessing students' writing.'

In a similar vein, most of the students $(\mathrm{N}=22)$ believed that in writing assessment, their teachers should utilize their own perceptions rather than utilizing a standard and available rubric. A couple of the students, on the other hand, $(\mathrm{N}=8)$ thought their teachers should make use of available and well-known rubrics when assessing 
the writings, which was opposed to their teachers' perceptions. One of the students said, 'While assessing the writings, I think, our teacher should not check a rubric and then grade us based on the rubric. I think based on his personal perceptions, he should assess our writing.' While another student stated, 'Yes, I think our teacher should utilize a standard rubric in assessing the writings. He should write comments for us and check every item and then grade the writings, I think.'

With regard to assessing language issues (grammatical problems), all of the teachers believed that the mistakes should be identified but their perceptions were different from those of the students with regard to the type of feedback which they should give to students. Three of the teachers thought that they should ask the students to revise the incorrect parts, but two of them believed that the correct forms should be provided and the students should be asked to practice them. Teacher 3, stated, 'I think the assessor should indicate the incorrect part which is grammatical problem by a red circle and want the students to correct it and revise the writing.' Teacher 2 said, 'I believe the teacher should draw a line under the grammatical problem and write the correct form and ask the students to check their mistakes and practice more.'

In line with teachers' perceptions, all of the students believed that the incorrect parts should be indicated by the assessor. Most of the students $(\mathrm{N}=19)$ believed that the grammatical problems should be indicated and revised later by the writer. Some of them $(\mathrm{N}=7)$ believed the correct forms should be provided and a couple of the students believed that the assessor should write comments and explain why the sentence is wrong grammatically and teach that part later in the class. As an example, one of the students who believed the grammatical problems should be revised by the student said, 'Grammar is very important in writing. I think grammatical problems should be revised by the student. The assessor can indicate where the sentences are grammatically incorrect and asks the students to correct the mistakes and revise the writing.' With regard to the belief that the correct form of mistakes should be provided, one student said, 'I think the person who assesses the writings should indicate the incorrect parts with regard to grammar and write the correct forms beside them. By doing so, the students will be exposed to the correct form and learn.' Moreover, another student believed, 'grammatical problems should be identified and indicated and later, the teacher should teach them in the class in order for the students to avoid making the same mistakes later in writings.'

All of the teachers believed that writing cannot be assessed indirectly through multiple-choice questions. Teacher 5 stated, "Of course not! Students should write to show their ability in writing. Writing is not an ability which teacher can evaluate and check by multiple-choice questions." 
In line with the perceptions of the teachers, most of the students $(\mathrm{N}=27)$ believed that using multiple-choice questions is not a good way of assessing students' writing ability. But, three of the students held an opposite view thinking that writing can be assessed through multiple-choice questions. One of the students said, 'In multiple-choice questions, you can distinguish between the correct and the incorrect form and structure which can be a way to assess writings.' On the other hand, one of the students said, 'To assess writing, you should write. You cannot assess writing ability by multiple-choice questions. You don't write in those questions, you only select the correct answer. This is not writing.

Regarding the reliability of the scoring procedures, all of the teachers did agree with this belief that scoring writing is always inaccurate and subjective and stated that different teachers have different approaches to assessing writing. For example, Teacher 1 stated, 'Well, yes, I do agree with this belief. Because assessing students' writing is something subjective. It is not like a multiple-choice test which you can easily and objectively assess it.'

On the other hand, although most students $(\mathrm{N}=19)$ had similar perceptions to those of the teachers, some of them $(\mathrm{N}=11)$ held different perceptions believing that scoring writing is not inaccurate and subjective. While one of the students believed 'The assessor grades the writing following his/her own perceptions. The scores will vary based on assessors' taste so, writing score cannot be accurate and subjectivity affects them'; another one said, 'The scores are not inaccurate and subjective. I think teachers' personal feelings and perceptions don't affect the scores. They check everything in the writings and then based on the performance, grade the writings.'

Finally, while three of the teachers believed that grammatical and lexical accuracy is more important than content, two of them believed that both content and accuracy (grammatical and lexical) are equally important in assessing writings. For example, Teacher 1 said, 'I think both the content and language accuracy are important in assessing writing. Teachers shouldn't ignore one of them at the expense of another. Both should be assessed equally.' Teacher 3, on the other hand, maintained, 'In assessing students' writing, I think focus on grammatical and lexical accuracy should be checked. In my opinion, students should use grammatical structures accurately and use appropriate words in their writings.'

In line with the teachers' view, most of the students $(\mathrm{N}=23)$ believed that accuracy is more important than content; nevertheless, some of them stated that both content and accuracy are important and the assessor should pay attention to them equally when assessing the writings. One of the students who believed accuracy (grammar) 
is more important said, 'In assessing a piece of writing, I think grammar is more important than content. If the writer doesn't use grammar accurately, it causes misunderstanding of the text.' One of the students who believed both content and accuracy (grammar) are equally important said, 'I think both are important. The content should be relevant to the topic and also the grammar should be used accurately. The assessor should check both when assessing writings.'

The above-mentioned results contribute to finding the answer to the first research question of the study. As is evident, a comparison of teachers' and students' perceptions revealed that there were some areas of overlap between these two groups' perceptions; for instance, most of the participants of the two groups believed that writing cannot be assessed indirectly through multiple-choice questions and scoring writing is always inaccurate and subjective. This finding supports the findings of previous research such as those of Raczynski, Cohen, Engelhard, and $\mathrm{Lu}$ (2015), which demonstrated that some essays are significantly more difficult to be scored accurately than other essays for professional raters like professors and reviewers. This finding is also in line with what Wolfe, Song, and Jiao (2016) found as features of difficult-to-score essays for professional raters. Results of their study revealed that essay length and lexical diversity accounted for $25 \%$ of the variances in the difficulty of accurately scoring an essay.

Also, Wang, Engelhard, Raczynski, Song, and Wolf (2017), found that raters had inconsistent perceptions toward certain features of essays compared to the experts, such as the amount of textual borrowing, the development of ideas, and the consistency of the focus. In addition, findings of the previous study support the findings of Marefat and Heydari (2016), which showed that native and non-native raters rate the same writing samples differently. Also, Marefat and Heydari (2016), believed that a multiple-draft approach should be used in the classes. In this regard, Ferris (1997), concluded that although students paid some attention to their teacher's feedback, they did not fully take into account their teacher's comments when revising their writings. Moreover, both groups believed that teachers should utilize their own perceptions rather than using standard and available rubrics. These findings contradict Obeid's (2017), results which suggested that most of the teachers and learners perceived using a rubric in assessing a piece of writing has a couple of advantages which cannot be ignored. That is, the researcher found that using a rubric will clarify the expectations teachers have of their learners. Also, it was found that rubrics serve as tools to identify the strengths and weaknesses in learners' writing performance and also an opportunity to direct learners toward self-evaluation.

However, some discrepancies could also be found between the perceptions held by these two groups. To put it more clearly, teachers believed that language, 
punctuation, content, organization, and communicative achievement are important factors which should be considered in writing assessment while students mentioned just grammar and spelling. These findings are partly in line with the findings of Khongput (2017) who found that most teachers perceive relevant development of ideas, organization, cohesion, task completion, appropriate vocabulary use, appropriate grammar, and mechanics as very important factors in assessing a piece of writing. However, when considering the relative importance of each of these factors, the latter study suggested that relevant development of ideas, organization, and cohesion were perceived as the most important while mechanics was perceived as the least important, which is in contrast to the findings of the current study. In addition, teachers believed that composition writing, open-ended questions, and summarizing are activities which can be used to assess writing while students believed that writing can be assessed through composition writing and writing definitions of terms and concepts.

To put it in a nutshell, it can be argued that although some similarities could be observed between teachers' and students' perceptions of L2 writing assessment, their ideas did not match completely. The main area of mismatch was their perceptions of criteria for assessing writing. Hence, while teachers considered a broader range of criteria, students perceived that a more limited number of criteria should be taken into account. Although it can safely be argued that from both groups' point of view, mechanics of writing (i.e., language and punctuation) received the most attention, for teachers, besides mechanics, other criteria (i.e., content, organization, and communicative achievement) were also worth considering of which students were not aware. This mismatch could threaten students' written performance because as indicated by results of previous research, such mismatches can have negative impacts on students' achievement (e.g., Williams \& Burden, 1997). To examine the potential effect of such mismatches, in the last part of this study, the researchers endeavored to find out whether, in this particular sample of the participants, these mismatches would lead to a parallel divergence between the scores given by the teachers to the students' writings and the scores the students themselves gave to their own writings which were indicative of their expectations of the evaluation of their own writing performance.

\section{The effects of (mis)matches between teachers' and students' perceptions of the scores given to the written work}

In order to answer the second research question, an independent-samples t-test was conducted to compare the writing scores of teachers and students. It is worth mentioning that both teachers and students were asked to try to articulate their thoughts aloud while doing the assessment; that is, to think aloud. Similar to their 
perceptions, all of the teachers considered language (grammar and vocabulary) while assessing the written work. Also, all of the teachers except for Teacher 2 believed that content is an important criterion in assessing written work. Interestingly, none of the teachers except for Teacher 1 paid attention to the content. That being so, while assessing one of the written works, for instance, she said, 'Well, in her writing, as I checked, each paragraph is appropriately related to the topic and the student has done what she was asked to do.'

With regard to organization, only two of the teachers believed that organization is important in a piece of writing and should be checked by the assessor. In their practice, both of them considered organization but the rest of the teachers did not pay any attention to the organization as they did not perceive it to be an important criterion in assessing students' written work.

While just one of the teachers, Teacher 3, believed that communicative achievement is important in writing assessment, none of them considered it in their practice. Finally, whereas all of the teachers believed that punctuation is an important criterion in assessing students' writing, only three of them considered and checked the punctuation. As an example, Teacher 5 said, 'There should be a comma here ... here the student has used a direct quote, but he did not use a quotation mark ... again here he made a mistake in using comma.' But the other two teachers did not check punctuation marks.

Similar to their perceptions, all of the students considered grammar while assessing the written work. One of them, Student 5 said, "Here the tense of the verb is not right. The verb should be past tense while here it is in present tense... again here I can see the same mistake with the tense of the verb. With regard to spelling, just one student considered it while assessing the writing. He said, 'This word is not correct in terms of spelling. Instead of 'ae' I have used 'ea' which is wrong. Also, here, again there is spelling mistake.'

With regard to the scores which teachers and students assigned to the writings they assessed, as tables 1 and 2 show, there was a significant difference in the scores assigned by the teachers $(M=14.60, S D=1.32)$ and the ones assigned by the students $(M=17.20, S D=.99 ; t(58)=8.57, p=.00$, two-tailed). The magnitude of the differences in the means (mean difference $=2.60,95 \%$ CI: 1.99 to 3.20 ) was very large (eta squared $=.558)($ Pallant, 2011).

These results suggest that divergence between the teachers' perceptions and those of their students could have negative effects on the students' achievement in that based on their own perceptions of the criteria for writing assessment, the present students expected to receive higher scores than the ones given by their teachers. 


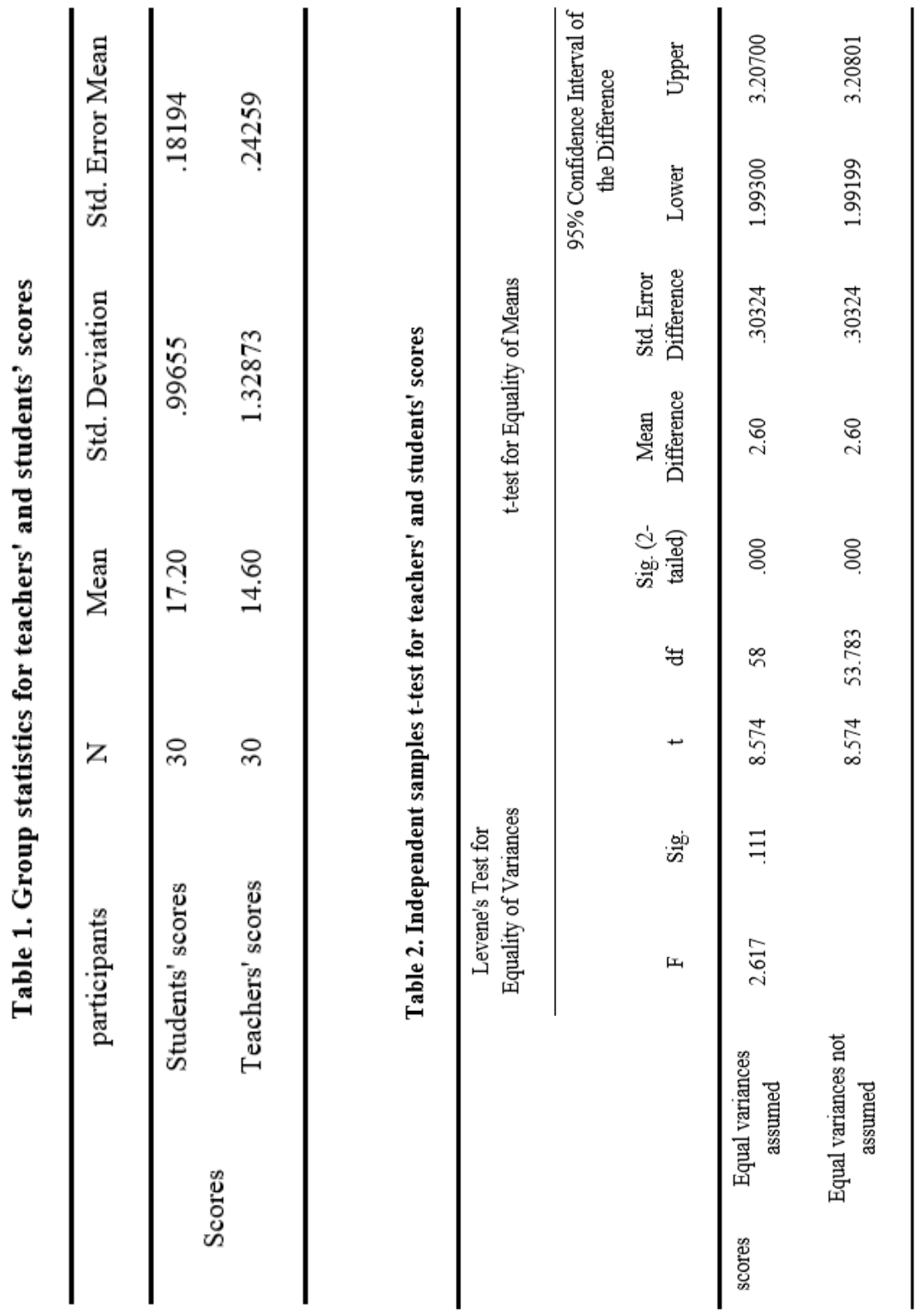


These results indicate that the lack of congruence between teachers' and students' perceptions of writing assessment could affect students' performance negatively. That is, while the students in this study expected to receive higher scores for their writings ( $M=17.20)$ gave them lower scores $(M=14.60)$. Also, the results showed that there was a mismatch between teachers' and students' perceptions and their actual practices. This hypothesis enjoys the support of previous research such as the one conducted by Williams and Burden (1997) who argued against the negative effects of such mismatches on students' achievement. Moreover, in line with the same finding, Horwitz (1990), Kern (1995), and Schulz (1996) rightly put that such mismatches between students' and teachers' expectations can also have negative effects on L2 students' satisfaction with the language class. On the other hand, even if these mismatches do not lead to negative effects on students' achievement, they may result in disillusionment on the part of the students (Brown, 2009). It is, therefore, suggested that more studies be done in the future in this area to see whether these findings will be confirmed or refuted in other parts of the world.

\section{Conclusion}

Considering the dynamic and changing nature of perceptions (Barcelos \& Kalaja, 2003; Brown, 2009) as well as the need to match teachers' and students' perceptions to the extent possible, this study was an attempt to investigate Iranian institute EFL teachers' and students' perceptions of assessing students' L2 written performance. It also intended to examine the possible effects of any (mis)matches on students' achievement.

All in all, considering Iranian teachers' and students' perceptions from different angles, one can come to the conclusion that while there were some areas of overlap, their perceptions differed in some respects. Specifically, regarding criteria for L2 writing assessment, each group referred to a different set of criteria. Considering this finding, it may not be unreasonable to envisage that such mismatches can, in practice, have detrimental effects on teaching of English writing. As was conspicuously found, divergence between the teachers' perceptions and those of their students could have negative effects on students' achievement in that based on their own perceptions of criteria for writing assessment, the present students expected to receive higher scores than the ones given by their teachers.

Some practical and pedagogical implications can be extrapolated from the findings of this study. Regarding teachers, given the fact that the participating teachers in this study admitted they had not passed any relevant courses in either writing 
instruction or its assessment, it seems urgent that some training courses be offered to Iranian EFL institute teachers in which they can learn the necessary writing instruction and assessment strategies. Moreover, they also need to be made familiar with the available and the most up-to-date writing assessment rubrics and to be taught how to use them objectively.

As regards the Iranian EFL institute students, results indicated that they had a limited knowledge of writing assessment criteria, which may imply that they write their assignments based on this limited number of criteria they have in mind. In order to broaden their knowledge of such criteria, it is suggested that, prior to asking them to write something, their teachers teach them and raise their awareness of different aspects of writing which warrant consideration and attention.

As the present findings showed, mismatches between teachers' and students' perceptions of criteria for writing assessment may have adverse effects on the students' final achievement scores. This points out the need for more teacherstudent negotiations and discussions on writing and writing assessment. By listening to the voice of the students through needs analysis procedures, teachers and other responsible stakeholders can realize their needs and design more suitable syllabuses to offer more useful courses. As part of the process of syllabus design, the role of writing textbooks and materials can by no means be denied.

This study, like most other studies, is not void of some limitations. The first limitation concerns the small sample size; that is, a limited number of teachers and students participated in this study, which cannot properly represent the whole population of EFL institute teachers and students in Iran. Moreover, this study was conducted in English language institutes and did not take into account public high schools or other contexts which might approach writing instruction and assessment in different ways. Considering these shortcomings, future research can take special measures to alleviate some of the above-mentioned problems by, for instance, randomly choosing the participants from a population of institute teachers and students. Other studies can also investigate teachers' and students' perceptions toward the issue in high schools or universities. As another suggestion, variables such as gender, age, and level of proficiency could be included to examine whether or not these variables may bring about any difference in students' perceptions towards the issue.

\section{References}

Ary, D., Jacobs, L. C., Sorensen, C., \& Razavieh, A. (2010). Introduction to research in education (7th ed.) Belmont, CA: Thomson \& Wadsworth.

Barcelos, P., \& Kalaja, A. M. F. (2003). Beliefs about SLA: New research approaches. 
Amsterdam, The Netherlands: Kluwer Academic.

Brown, A. V. (2006). Students' and teachers' perceptions of effective teaching in the foreign language classroom: A comparison of ideals and ratings. Unpublished M.A. thesis, University of Arizona, USA. Retrieved from http://hdl.handle.net/10150/195302.

Brown, A. V. (2009). Students' and teachers' perceptions of effective foreign language teaching: A comparison of ideals. The Modern Language Journal, 93, 46-60.

Brinke, D. J., Bruggen, J. V., Harmans, H., Burgers, J., Giesbers, B., Koper, R., \& Latour, I. (2007). Modeling assessment for re-use of traditional and new types of assessment. Computers in Human Behavior, 23, 2721-2741.

Crowley, S. (1998). Composition in the university. Pittsburgh, PA: University of Pittsburgh.

Dahlgren, L. (1984). Outcomes of learning, in the experience of learning. Edinburgh: Edinburgh University Press.

Eun, H. (2015). A study on perceptions of feedback between students and teachers in English writing course. Studies in English Language \& Literature, 41(3), 203-232.

Ferris, D. R. (1997). The influence of teacher commentary on student revision. TESOL Quarterly, 31, 315-339.

Horwitz, E. K. (1990). Attending to the affective domain in the foreign language classroom. In S. Magnan (Ed.), Shifting the instructional focus to the learner (pp. 15-33). Middlebury, VT: Northeast Conference on the Teaching of Foreign Languages.

Kaplan, R. B. \& Grabe, W. (2002). A modern history of written discourse analysis. Journal of Second Language Writing, 11 (3), 191-223.

Kern, R. (1995). Students and teachers' beliefs about language learning. Foreign Language Annals, 28, 71-92.

Khongput, S. (2017). EFL writing assessment practices: Teachers' perspectives. Retrieved from http://www.iaea.info/documents/paper_4d32ee9a.pdf

Leki, I. (2003). A challenge to L2 writing professionals. Is writing overrated? In B. Kroll (Ed.) Exploring second language writing, (pp.315-331). New York: Cambridge University Press.

Marefat, F., \& Heydari, M. (2016). Writing native and Iranian teachers' perceptions and evaluation of Iranian students' English essays. Assessing Writing, 27, 24-36.

Montgomery, J. L., \& Baker, W. (2007). Teacher-written feedback: Student perceptions, teacher self-assessment, and actual teacher performance. Journal of Second Language Writing, 16, 82-99.

Neumann, H. (2014). Teacher assessment of grammatical ability in second language academic writing: A case study. Journal of Second Language Writing, 24, 83-107.

Obeid, R. (2017). Second language writing and assessment: Voices from within the Saudi EFL context. English Language Teaching, 10(6), 174-187.

Pallant, J. (2011). SPSS Survival manual: A step by step guide to data analysis using SPSS for windows. New York: McGrew Hill.

Raczynski, K. R., Cohen, A. S., Engelhard, G., \& Lu, Z. (2015). Comparing the effectiveness of self-paced and collaborative frame-of-reference training on rater accuracy in a large-scale writing assessment. Journal of Educational Measurement, 52(3), 301-318. 
Reilly, J. (2005). Writing with children. Oxford: Oxford University Press.

Schulz, R. A. (1996). Focus on form in the foreign language classroom: Students' and teachers' views on error correction and the role of grammar. Foreign Language Annals, 29, 343-364.

Struyven, K., Dochy, F., \& Janssens, S. (2005). Students' perceptions about evaluation and assessment in higher education: A review. Assessment and Evaluation in Higher Education, 30(4), 325-341.

Wang, J., Engelhard, G., Raczynski, K., Song, T., \& Wolfe, E. W. (2017). Evaluating rater accuracy and perception for integrated writing assessments using a mixed-methods approach. Assessing Writing, 33, 36-47.

Williams, M., \& Burden, R. (1997). Psychology for language teachers. A social constructivist approach. Cambridge: Cambridge University Press.

Wolfe, E. W., Song, T., \& Jiao, H. (2016). Features of difficult-to-score essays. Assessing Writing, 27, 1-10.

Wolsey, T. D., Lapp, D., Fisher, D. (2012). Students' and teachers' perceptions: An inquiry into academic writing. Journal of Adolescent \& Adult Literacy, 55(8), 714-724. 